\title{
Ascensão Social de um Discente com Baixa Visão por meio dos estudos: da educação básica à universidade
}

Social ascension of an undregraduate student with poor vision through studies: from basic education to university

\section{Ana Lúcia Oliveira Aguiar}

Universidade do Estado do Rio Grande do Norte

(UERN/BRASIL),

oliveiraaguiarpetro@gmail.com

Stenio de Brito Fernandes

Secretaria de Educação e da Cultura do Estado do Rio Grande do Norte (SEEC/RN/BRASIL),

steniondre@hotmail.com

Aleksandra Nogueira de Oliveira Fernandes

Instituto Federal de Educação, Ciência e Tecnologia do Rio Grande do Norte (IFRN/BRASIL),

aleksandra.nogueira@ifrn.edu.br

Recibido el 27/10/2018

Revisión del 14/01 al 20/05/2019

Publicación 26/06/2019 


\section{Resumo}

Este artigo nasce de um projeto ligado à linha de pesquisa Práticas Educativas, Cultura, Diversidade e Inclusão, realizado pela Pró-Reitoria de Pesquisa e PósGraduação (PROPEG) da Universidade do Estado do Rio Grande do Norte (UERN/BRASIL). O estudo tem por objetivo compreender como o êxito escolar de um discente do curso de Direito da UERN, de camada popular e com baixa visão, contribuiu para conquistar sua ascensão social, desde a Educação Básica até a Educação Superior. Trata-se de uma pesquisa de abordagem qualitativa, com base na História Oral, a partir de narrativas (auto)biográficas, as quais permitem um processo formativo e autoformativo na escrita de si e com o outro. O acesso e a permanência do discente na sua trajetória entre a Educação Básica e a Universidade é fruto do apoio familiar e do acompanhamento da Diretoria de Políticas e Ações Inclusivas (DAIN) da UERN. As lições e aprendizagens passadas pela família e o acompanhamento de uma Equipe Multiprofissional da DAIN contribuem para a formação do discente, empoderando-o na luta pela superação de barreiras arquitetônicas, físicas e atitudinais vivenciadas nos espaços social e acadêmico..

Palavras-chave: discente, baixa visão, ascensão social, inclusão, Ensino Superior. 


\begin{abstract}
This article is born from a project linked to the research line Educational Practices, Culture, Diversity and Inclusion, carried out by the Pro-Rectory of Research and Postgraduate Studies (PROPEG) of the State University of Rio Grande do Norte (UERN / BRAZIL). The aim of this study is to understand how the success of a UERN undergraduate student at the popular level and with poor vision has contributed to his social progress from Basic Education to Higher Education. It is a qualitative research, based on Oral History, from (auto)biographical narratives, which allow a formative and self-formative process in the writing of the self and of the other. The access and permanence of the student in his trajectory between Basic Education and the University is a result of the help of the family and the support of the Directorate of Policies and Inclusive Actions (DAIN) of UERN. The lessons learned by the help of the family and by the support of a Multiprofessional Team of the DAIN contribute to the formation of the student, empowering him in the struggle to overcome architectural, physical and attitudinal barriers experienced in social and academic contexts.
\end{abstract}

Keywords: student, low vision, social ascension, inclusion, higher education. 


\section{Introdução}

O presente artigo nasce de um projeto vinculadoo à linha de pesquisa Práticas Educativas, Cultura, Diversidade $e$ Inclusão, realizado pela Pró-Reitoria de Pesquisa e Pós-Graduação (PROPEG) da Universidade do Estado do Rio Grande do Norte (UERN/BRASIL). Intitulado Ascensão Social de estudantes de origem popular por meio dos estudos: da Educação Básica até a Universidade, o projeto tem como propósito observar, sob a perspectiva inclusiva, discentes acompanhados pela Diretoria de Políticas e Ações Inclusivas (DAIN)' ${ }^{1}$. Neste estudo, o sujeito é um discente de camada popular do curso de Direito que tem baixa visão, escolhido dentre aqueles que estão envolvidos diretamente com o acompanhamento na DAIN.

Desenvolvido desde agosto de 2017, o projeto institucional permitiu a

1 O Departamento de Apoio à Inclusão (DAIN) foi criado pela Resolução n 2/2008 do Conselho Universitário - CONSUNI, de 18 de abril de 2008 e, em 2010, passa à Diretoria de Apoio à Inclusão, através da Resolução № 31/2010-CD. Em 24 de março de 2015, através da Resolução № 05/2015-CD, passa à Diretoria de Políticas e Ações Inclusivas.

${ }^{2} \mathrm{O}$ nome Herói é fictício, escolhido pelo próprio narrador, pois, esse nome tem um significado pela luta e perseverança de vencer os obstáculos do seu dia a dia. construção desse artigo como atividade de pesquisa. $O$ estudo tem por objetivo compreender, por meio de narrativas (auto)biográficas, como o êxito escolar de um discente do curso de Direito da UERN, de camada popular e com baixa visão, vem contribuindo para sua ascensão social desde a Educação Básica. A investigação partiu da seguinte questão: como um discente do curso de Direito da UERN, de camada popular e com baixa visão, vem conquistando sua ascensão social desde a Educação Básica por meio dos estudos?

O entrevistado mora na cidade de Icapuí, localizada no litoral leste do Ceará, com população estimada em 19.385 habitantes, em 2009. Sobre os avanços e perspectivas da Educação Inclusiva, torna-se relevante o ingresso de discentes da camada popular e 


\section{Metodologia de trabalho}

com deficiência no Ensino Superior. O entrevistado, filho de mãe doméstica e pai mestre de obras, recebeu o nome fictício de Herói ${ }^{2}$. A escolha do nome foi inspirada no esforço e na dedicação dos pais, o que permitiu seu ingresso no curso de Direito da UERN.

O discente vem participando ativamente em programas e projetos oferecidos pela DAIN/UERN, tais como: Programa Institucional de Iniciação em Desenvolvimento Tecnológico e Inovação (PIBITI), Programa Institucional de Bolsas de Iniciação Científica (PIBIC) e Projetos de Extensão.

Este artigo encontra-se organizado em duas partes: na primeira, abordaremos a trajetória educacional do discente com baixa visão antes do acesso à Universidade. $\mathrm{Na}$ segunda parte, enfocamos a ascensão social desse discente do curso de Direito da UERN por meio do êxito escolar.
Trata-se de uma pesquisa qualitativa ancorada nas lições de Minayo (1994), segundo as quais as ciências sociais possuem instrumentos e teorias capazes de fazer uma aproximação da suntuosidade que é a vida dos seres humanos em sociedades, ainda que de forma incompleta, imperfeita e insatisfatória. Segundo a autora, a pesquisa qualitativa reflete um conjunto de expressões humanas constantes nas estruturas, nos processos, nos sujeitos, nos significados e nas representações.

Utilizamos como método de investigação a pesquisa (auto)biográfica, com base na História Oral, a partir de narrativas, apoiada teoricamente em Josso (2010), Souza (2006) e Delory Momberger (2008). Para Josso (2010), a metodologia da pesquisa (auto) biográfica dá legitimidade à mobilização da subjetividade como modo de produção do saber e à intersubjetividade como suporte do trabalho interpretativo e de construção de sentido para os autorrelatos. Souza (2006) reforça que, por meio da abordagem biográfica, 0 sujeito produz um conhecimento sobre 


\section{Trajetória educacional antes do acesso à Universidade}

si, sobre os outros e sobre o cotidiano, revelando-se através da subjetividade, da singularidade, das experiências e dos saberes.

A história desse discente com baixa visão representa o que afirma Delory Momberger (2008, p. 99): "as histórias de vida se situam, deliberadamente, do lado do processo de mudança global da pessoa e da relação do formando com o saber e com a formação". Acrescentamos as teorias de Alberti (2005), que consideram as entrevistas de histórias de vida como de interesse do próprio indivíduo na história.

As entrevistas com o discente foram realizadas na sala do Grupo de Estudos e Pesquisas em Educação, Memórias (Auto)Biográficas e Inclusão (GEPEMABI), no Campus Central da UERN - Mossoró/ $\mathrm{RN}$, e contou com duas sessões de narrativas do discente, que aceitou participar voluntariamente da pesquisa.
Sobre os avanços e as perspectivas da Educação Inclusiva, é possível afirmar que se torna relevante a efetivação de discentes de camada popular com deficiência no Ensino Superior. As convenções, com destaque à Convenção Internacional dos Direitos da Pessoa com Deficiência, aprovada pela Organização das Nações Unidas, em 2006, estão relacionadas a leis, portarias e decretos aprovados ao longo da história da Educação Inclusiva no Brasil e no Mundo que buscam contemplar as diferentes deficiências e o respeito aos princípios da diversidade humana.

Segundo Bittencourt e Camargo (2010), é preciso o reconhecimento da identidade e das possibilidades das pessoas com deficiência a partir da construção das ações dos marcos legais da Educação Inclusiva. Para isso, as autoras salientam a importância do empenho e engajamento de toda a sociedade, para que possamos concretizar a inclusão, através da prática e da sensibilização dos sujeitos.

O discente com baixa visão relembra, em suas narrativas, a infância, a 
adolescência, o cotidiano na escola na sua cidade. As experiências formativas vivenciadas por ele são compartilhadas com a família e com os colegas, na escola e na universidade. Segundo Josso (2010), a formação se distingue de dois modos: como um processo de mudança; e como projeto, produção de sua vida e de seu sentido. Ambos são importantes para que o discente, através da aprendizagem, desenvolva e desempenhe um papel decisivo em sua formação.

Herói é um rapaz, filho de mãe doméstica e de pai mestre de obras, que mora na cidade de Icapuí/CE e já trabalhou como agricultor e como pescador artesanal. Com o esforço e a dedicação de seus pais, conseguiu ingressar na UERN, onde cursa Direito e vem participando, através da DAIN, de iniciativas como o PIBITI, PIBIC e Projetos de Extensão. A baixa visão foi diagnosticada no período de sua infância. Através dos exames, os médicos detectaram o glaucoma congênito. $O$ entrevistado conta como tudo começou:

[...] meus pais descobriram o glaucoma através de uma consulta com um oftalmologista, desses oftalmologistas que vem nos bairros esporadicamente através das óticas. Então, minha mãe levou eu e o meu irmão também. Descobriu que o meu irmão tinha miopia eque eu tinha um problema mais grave, que necessitava de se tratar com urgência. [...] Os meus pais me levaram à Fortaleza. Lá, tinha um médico muito famoso, o Leiria de Andrade. Então, ele me encaminhou pro Instituto dos Cegos de Fortaleza. Lá, eu fiz três cirurgias. Que posteriormente eu fui transferido para o Hospital Geral de Fortaleza, onde eu fiz outras cinco cirurgias (Narrativas de Herói, em Mossoró/RN, 20/07/2017).

Herói, em suas narrativas, enfoca a descoberta da sua deficiência e as indicações médicas. Ele relembra que, quando passou a usar óculos, sofria com tonturas e caía muito. Construiu um percurso de adaptações. Em suas brincadeiras, Herói conta que às vezes tropeçava bastante e tinha o apoio das demais crianças, dizendo: "eles tinham uma preocupação comigo". Com o suporte da família, logo foram buscar, em Fortaleza/CE, um tratamento mais eficaz para o problema do glaucoma. O Decreto de № 5.926/04 (Brasil, 
2004, p. 2) diferencia cegueira e baixa visão:

[...] cegueira, na qual a acuidade visual é igual ou menor que 0,05 no melhor olho, com a melhor correção óptica; a baixa visão, que significa acuidade visual entre 0,3 e 0,05 no melhor olho, com a melhor correção óptica; os casos nos quais a somatória da medida do campo visual em ambos os olhos for igual ou menor que 600; ou a ocorrência simultânea de quaisquer das condiç̧̃es anteriores [...].

De acordo com Amiralian (1997), a cegueira adquirida é uma perda irreversível que provoca profundas mudanças e cujos efeitos sobre a personalidade estão relacionados à fase de desenvolvimento em que se encontra o sujeito, a forma de instalação da cegueira (súbita ou progressiva), e as condições pessoais e familiares do sujeito antes da ocorrência do problema. Freitas (2018) explica que o empoderamento dos sujeitos com baixa visão contribui de maneira plena para que todos alcancem meios viáveis para inclusão, tolerância e respeito nos espaços escolares e não escolares.
Nesse momento, Herói narra o percurso trilhado na sua vida educacional, passando pela Educação Infantil, Ensino Fundamental I e II e o Ensino Médio até chegar à Universidade. Ao expressar seus sentimentos e relatar sonhos e dificuldades conquistadas ao longo do percurso escolar, percebemos como os estudos foram importantes para alcançar sua ascensão social. A trajetória mostra a importância da vida social para inclusão, os caminhos percorridos e os sonhos a serem alcançados. $O$ discente relata uma passagem vivenciada no Ensino Fundamental I e explica:

No $3^{\circ}$ ano [...] meus pais tinha comprado um óculos, e com esses óculos, eu tive uma melhora [...], eu lembro que usava óculos, nas séries iniciais, nessa época eu mudava de óculos com rapidez, era uma questão de ano, em ano em ano trocava de óculos, porque, como, eu fazia bastante cirurgia e usava muito medicamentos, então, se alterava as possibilidades de enxergar. Aí, então, eu trocava, com frequência de óculos (Narrativas de Herói, em Mossoró/ RN, 20/07/2017). 
Devido ao agravamento da doença visual, Herói se submeteu a várias cirurgias e era frequente a troca de óculos. Em suas narrativas, relembra que escrevia "torto", fora do campo das linhas do caderno. Com os resultados das cirurgias, as professoras notaram uma melhora significativa no desempenho na sala de aula. Herói comenta, em suas narrativas, a falta de atenção de uma professora e diz: [...] "na verdade, ela não tinha uma preocupação mesmo, porque ela sabia que eu tinha problema e não era atenciosa". Diante dessa lembrança, Herói relata:

[...] não conseguia visualizar os cálculos que estavam na lousa, não conseguia ver as letras. Quando chegava minha vez pra ler, eu dizia que não sabia ler. Assim, a professora passava a oportunidade pra outro colega. Ou seja, ela não se preocupava comigo, se dava pra eu enxergar lá do canto que eu ficava. Isso fez com que eu tivesse um grande atraso na escola (Narrativas de Herói, em Mossoró/ RN, 20/07/2017).

Diante da falta de apoio da professora mencionada em suas narrativas, Herói se sentiu excluído, gerando nele certo desinteresse. Com isso, sua mãe sentiu a necessidade de colocá-lo na aula de reforço ${ }^{3}$ para acompanhar e orientar as atividades da escola. Segundo Herói, as aulas de reforço ajudaram a desenvolver o seu processo de alfabetização, repercutindo na reação das professoras, pois ficaram surpresas com seus avanços na aprendizagem. Esse resultado foi visível, como conta em suas narrativas, dizendo: "até teve um concurso de cálculo na segunda série, eu fiquei em primeiro lugar. Ganhei a fama de ser um dos melhores alunos de minha escola". O apoio da família e o acompanhamento da escola foram um passo importante para o crescimento e aprendizagem de Herói, mas, através de um olhar atento, sensível e mediador de outra professora, o aluno com baixa visão se supera diante de suas limitações, como afirma Mantoan (2003, p. 15):

O processo de integração ocorre dentro de uma estrutura educacional que oferece ao aluno a oportunidade de transitar no sistema escolar - da classe regular ao ensino especial - em todos os seus tipos de atendimento: escolas especiais, classes especiais em escolas comuns, ensino itinerante, salas de recursos, classes hospitalares, ensino domiciliar e outros. 
É na escola que acontece o processo de integração citado pela autora. No Ensino fundamental II, Herói relata sua convivência com a professora da disciplina Língua Portuguesa e diz: "tive a sorte de pegar uma professora muito atenciosa [...] Ela lia as provas pra mim, pois não conseguia enxergar as linhas fracas, as provas eram rodadas no mimeógrafo". A atitude e atenção da professora fortaleceu no discente o desejo de participar das atividades propostas pela escola e em sala de aula. Através do apoio da professora, Herói conheceu um projeto de inclusão para pessoas com deficiência. A professora estava à frente desse projeto, financiado pelo Banco do Nordeste ${ }^{4}$ para a cidade de Icapuí/CE, oportunizando todos a participarem de oficinas para aprender a fazer artesanatos.

Esse projeto motivou em Herói nova perspectiva inclusiva, como afirma em suas narrativas: "eu fui melhorando na minha aprendizagem na escola e passando a interagir mais com mais colegas, pois tinha passado também por uma época de isolamentos". Segundo Mantoan (2006), a educação inclusiva deve acolher todas as pessoas, sem exceção, respeitando as diferenças e garantindo o direito à educação.

De acordo com Josso (2010, p. 62, 63), "A reflexão biográfica permite, portanto, explorar em cada um de nós as emergências que dão acesso ao processo de descoberta e de busca ativa da realização do ser humano em potencialidades inesperadas". É nesse processo de descoberta que o discente narra o seu percurso no Ensino Médio:

Foi parecido com o ensino fundamental II [...] só que melhor ainda, porque no Ensino Médio, já era em outra escola Estadual. Então, tinha um suporte

\footnotetext{
${ }^{3} \mathrm{~A}$ aula de reforço tem o objetivo de auxiliar os estudantes com dificuldades de aprendizagem em acompanhar ou assimilar os conteúdos repassados pelo professor nas aulas regulares. O professor das aulas de reforço exerce um papel importante para a formação e para o aprendizado da criança, que passa a ter acesso a mais horas de estudo nas matérias que apontam dificuldades em compreender.
} 
maior, tinha biblioteca, é, tinha laboratório de informática com acesso a Internet, isso no interior [...] pra mim, foi um grande avanço, porque na minha escola que eu estudava anteriormente, não tinha acesso a Internet, as provas não vinham digitadas, era no mimeografo, e até dificultava a leitura, mas, depois que passei para essa escola estadual, as provas vinham com letras ampliadas, os professores davam bastante atenção. Eu lembro que, no primeiro dia de aula, meu pai veio conversar com a direção, a partir daí, eles me deram bastante atenção, ampliando as provas, uso de lupa, me deram suporte com relação aos equipamentos de acessibilidade, no caso da lupa (Narrativas de Herói, em Mossoró/ RN, 20/07/2017).

Na visão de Herói, o Ensino Médio trouxe bons resultadose permitiuum tratamento diferenciado por parte dos professores, dos colegas e da direção da escola. Por se tratar de uma escola estadual ${ }^{5}$, possuía mais recursos de inclusão digital, como o caso da lupa, que possibilitou um processo de aprendizagem diferente do vivenciado no Ensino Fundamental II, na escola municipal ${ }^{6}$. Para a adaptação da sua deficiência às atividades na referida escola, obteve duas lupas e as provas vinham com letra ampliada.

${ }^{4}$ O Banco do Nordeste do Brasil S.A. foi criado pela Lei Federal n 1649 , de 19.07.1952; é uma instituição financeira constituída na forma de sociedade de economia mista, de capital aberto, controlada pelo Governo Federal Brasileiro, tendo a União como sua acionista majoritária. Sua sede é localizada na cidade de Fortaleza, estado do Ceará. Designado para atuar no chamado Polígono das Secas, designação dada a perímetro do território brasileiro atingido periodicamente por prolongados períodos de estiagem. A empresa assumia então a atribuição de prestação de assistência às populações dessa área, por meio da oferta de crédito. Disponível em: https://www.bnb.gov.br/historico. Acesso: 16 nov. 2018. 
para ser expectador e fazer, em casa,

Quanto aos aspectos desafiadores, o discente destaca dois pontos: a biblioteca possuía poucos livros de literatura com letra ampliada, e ele não participava das atividades práticas das aulas de Educação Física, apenas permanecia presente na quadra para poder responder à chamada. Herói acrescenta: "diferentemente do ensino fundamental II, eu não precisava estar ali presente na quadra de esporte, podia ficar em casa, era totalmente dispensado, mas essa questão de Educação Física no Ensino Médio eu tinha que observar". Percebemos um descontentamento por parte do discente em relação às aulas de Educação Física; não havia a inclusão para as atividades: apenas teria que comparecer à quadra os trabalhos teóricos para valer como atividade avaliativa.

Quanto à questão do uso dos óculos, a baixa visão não cessou, devido ao glaucoma congênito, pois o problema de Herói se trata de uma doença cujos efeitos são irreversíveis e tendem à progressão se não houver controle; os óculos não eram suficientes para corrigir significativamente sua visão, devido à gravidade do problema. Mesmo com o uso dos óculos, Herói tem dificuldades de enxergar, principalmente as informações escritas no quadro branco. Sobre essa dificuldade o Herói conta:

As professoras escreviam no

\footnotetext{
${ }^{5} \mathrm{~A}$ escola estadual é uma instituição pública de ensino de educação básica e média criada e mantida pelos governos estaduais no Brasil. O Estado tem obrigações e metas a cumprir com a educação, parte disso está na criação e manutenção de escolas que ofereçam um ensino de qualidade. Disponível em: https://www.materias.com.br/escolas/escola-estadual-vantagens-e-desvantagens/. Acesso: 16 nov. 2018.
}
${ }^{6} \mathrm{~A}$ escola municipal é uma instituição pública que pertence ao município, a prefeitura de uma cidade tem a responsabilidade de contratar e pagar professores e funcionários; atende aos níveis de ensino da Educação Infantil até o Ensino Fundamental.


quadro mais moderno, porque lá na escola do interior o quadro era tradicional com giz, e, eu confesso que para visualizar era melhor, por conta do contraste do verde escuro e o giz branco, né? Ajudava muito, e no caso da escola do Ensino Médio, que era uma escola modernizada, aí, tinha esses quadros que hoje se usa aqui na UERN, e em outras universidades, no caso da lousa branca com pincel, aí, muito dificultoso para mim, sempre eu peço para os professores escrever com os pinceis preto, porque daquele contraste, já que o fundo é branco e a tinta preta, assim, ajuda muito, o bom seria que tivesse uma lousa preta com o pincel branco (Narrativas de Herói, em Mossoró/ RN, 20/07/2017).

Diante das dificuldades na sala de aula, Herói relata o apoio recebido dos colegas quando diz: "sempre os colegas me ajudavam a visualizar as letras, algumas palavras que estivessem apagadas na lousa, também tinha ajuda de alguns professores que se dedicavam muito, e davam uma atenção especial". Segundo Mantoan (2000, p.7), "esses ambientes educativos desafiam as possibilidades de aprendizagem de todos os alunos e as estratégias de trabalho pedagógico são adequadas às habilidades e necessidades de todos". Um passo relevante para a vida de Herói foi o apoio dado por sua família, pelo irmão e pelos pais, que estavam sempre preocupados em ajudá-lo. Em suas narrativas, o discente relata sobre a questão do horário das atividades:

Quanto à iluminação em casa, se eu fazia as atividades à noite, como eu estudava de manhã, aí, eu chegava em casa, já tinha que fazer à tarde, quando não conseguia fazer à tarde, tinha que entrar a noite para poder concluir a minha atividade para entregar na manhã seguinte, quando eu entrava a noite, tinha um descanso na minha vista, porque os trabalhos eram feitos a mão, manualmente. No caso, eu pedia ajuda ao meu irmão mais velho, que, ele escrevia com a letra dele, aí, quando meu pai comprou o computador, eu fiquei mais independente, em relação a essa questão (Narrativas de Herói, em Mossoró/RN, 20/07/2017).

O percurso educacional de Herói, do 
Ensino Fundamental até o Ensino Médio, marca sua história de vida de lutas e superações. As conquistas só foram possíveis pela colaboração de sua família, dos amigos, dos professores do Ensino Fundamental e Médio. $\mathrm{O}$ discente atribui à tecnologia um papel importante no seu processo de aprendizagem; em suas narrativas, Herói diz: "o computador facilitou bastante, aí, quando não tinha o computador eu usava como recursos a lupa virtual, e também, passei a utilizar leitura de tela, isso foi um grande avanço". No Ensino Médio, Herói relata que utilizava mais a lupa e letras ampliadas, depois começou os primeiros contatos com o leitor de tela, e explica: "com o agravamento do meu problema visual, eu passei a utilizar os leitores de tela". Entendemos que o uso do leitor de tela proporcionou um salto significativo para seu desenvolvimento. 


\section{Ascensão social de um discente por meio do êxito escolar}

Nesse segundo momento de discussão, abordaremos como os estudos contribuíram para a ascensão social do discente do curso de Direito da UERN de camada popular e com baixa visão: as políticas de Inclusão da Diretoria de Políticas e Ações Inclusivas (DAIN/UERN) na efetivação dos diretos no Ensino Superior. Por meio das narrativas de Herói ao ingressar no curso de Direito da UERN, percebemos que há relação entre sua ascensão social e o estudos, e surgiram algumas inquietações: Como o discente construiu sua trajetória de estudos no Ensino Superior que resultou no êxito social? Quais os avanços do discente através do acompanhamento da Diretoria de Políticas e Ações Inclusivas - DAIN/ UERN para sua formação? Que lições de aprendizagem Ensino Superior permitiram ao discente a quebra das barreiras atitudinais e arquitetônicas vivenciadas nos espaços social e acadêmico? Essas inquietações serão discutidas ao longo do texto, quando tratamos do acesso e da permanência de Herói no Ensino Superior.

É relevante destacar que o Ensino Superior desempenha um papel decisivo e fundamental no que diz respeito aos conteúdos de ensino, valores e habilidades que se incorporam nesse processo. Para Pinto (2008), a universidade deve se comprometer de maneira diferenciada com a formação dada para os seus alunos, especialmente no que se refere à sensibilização, para que eles enxerguem os problemas sociais que os rodeiam. Para que isso, de fato, aconteça, o autor afirma que será possível na medida em que os professores tiverem uma postura aberta à troca com os seus alunos, para que os estudantes se sintam capazes de integrar as iniciativas de responsabilidade social da universidade. Partindo da premissa de que a universidade tem um papel articulador no ensino, pesquisa e extensão, destacamos as políticas de Inclusão da UERN, através da DAIN. A DAIN é um órgão que tem a finalidade de contribuir para a inclusão de discentes com deficiências, oferecendoIhes condições para que tenham acesso a conhecimentos, informações, relacionamentos sociais e ambientes de estudos. As atividades desenvolvidas pela diretoria baseiam-se nas Legislações Nacionais e Internacionais de Educação 
sobre os Direitos das Pessoas com Deficiência.

A Diretoria da DAIN vem realizando atividades importantes para a valorização da inclusão através do Seminário Potiguar: Educação, Diversidade e Acessibilidade; Seminário de Narrativas (Auto)Biográficas: Encontro Regional de Narrativas (Auto)Biográficas (ERNAB). A DAIN está na sua $29^{\circ}$ Rodas de Estudos sobre a Lei Brasileira de Inclusão (LBI) - Lei No 13.146, de 06/07/2015. As reuniões envolvem diversos parceiros da Educação, da Saúde, da Assistência Social, do Judiciário e de entidades ligadas às pessoas com deficiência, como Centro Estadual de Capacitação de Educadores e Atendimento ao Surdo (CAS), Associação de Surdos de Mossoró (ASMO), Fórum das Mulheres com Deficiência, Associação dos Deficientes Físicos de Mossoró (ADEFIM), Centro de Apoio ao Deficiente Visual (CADV), Associação dos Deficientes Visuais (ADVM), Associação de Pais e Amigos dos Excepcionais (APAE), Centro Regional De Educação Especial De Mossoró (CREE-MOS).

A LBI trouxe avanços pertinentes para as pessoas com deficiência, pois retira a exclusividade de atribuição da deficiência à pessoa e divide atribuições e obrigações ao Estado e a diversos setores da sociedade, com o fito de realizar e intensificar a acessibilidade (FREITAS, 2018). As Rodas de Estudo oportunizam debates para refletir e discutir sobre a relevância de quebra das barreiras atitudinais, arquitetônicas e físicas, e procedimentais para a efetivação do Direito das Pessoas com Deficiência.

A DAIN trabalha de forma incansável para atuar nos três princípios que fundamentam as universidades ensino, pesquisa e extensão. Ao atuar na extensão, universidade e sociedade aproximam-se e constroem novos paradigmas de inclusão (FREITAS, 2018). Para garantir e efetivar a inclusão de discentes com deficiência, diferentes cursos de extensão são ofertados, tais como: Curso de Extensão em Língua Brasileira de Sinais, Curso de Extensão LEDOR, Curso de Extensão Orientação e Mobilidade, Curso de Extensão em Formação Continuada- Conceitos e Práticas em Educação Especial e Inclusão. Antes de ingressar no curso de Direto da UERN, Herói passou por algumas experiências de formação, construindo sua primeira experiência quando ingressou na licenciatura em Matemática 
na modalidade de Educação à Distância $(\mathrm{EaD})$, promovida pela Universidade Aberta do Brasil (UAB) em parceria com a Universidade Federal do Semiárido (UFERSA) - Mossoró/RN. Sobre essa experiência o entrevistado faz o seguinte relato:

\section{[...] Eu cheguei a cursar um} período, fui aprovado em todas as disciplinas, no primeiro período do curso de matemática, mas, aí, eu já tinha entrado no curso de Matemática, já no sentimento de fazer Direito também, aí, o bom seria se eu pudesse fazer as duas ao mesmo tempo, mas, por conta da questão do glaucoma e da limitação do tempo, eu optei a fazer só Direito mesmo, e, no caso do suporte que tive na primeira graduação que fiz em Matemática, né, no primeiro período, tive o suporte dos professores e teve uma professora que me fez ter um contato maior e profundo com as tecnologias assistivas, aí, ela foi falando do leque que tem de programas, de leitores de tela, de tecnologias, que até então eu não conhecia, aí, no caso, isso me preparou para que eu estudasse e me preparasse para o vestibular da UERN, porque eu queria fazer Direito, e então isso me preparou bastante [...] (Narrativas de Herói, em Mossoró/RN, 20/07/2017).

Através dessa experiência vivenciada na modalidade de Educação à Distância - EaD, o discente adquiriu novos conhecimentos, principalmente no contato com tecnologias assistivas, como equipamentos especiais, ajudas técnicas e softwares, que proporcionaram acesso ao conhecimentos e a informações, sem o entrave de barreiras. Quanto à preparação para participar do vestibular no ano de 2012, Herói conta como se preparou: "eu não tive nenhum cursinho preparatório, porque eu mesmo não quis fazer. Meu pai sempre me incentivou que eu fizesse um cursinho preparatório em Mossoró".

Com disciplina e dedicação, Herói optou por estudar em casa; ele explica que "fez planejamento com um calendário de estudos". Passar no vestibular para o curso de Direito na UERN era o maior objetivo de Herói, pois tinha certeza que iria concretizá-lo, mesmo diante do pouco tempo que tinha de preparação. $O$ discente logrou êxito sendo aprovado no vestibular para o curso de Direito. 
Somente em 2013 houve o primeiro Processo Seletivo Vocacional na UERN, com vagas destinadas para pessoas com deficiências. No vestibular de 2012, Herói relata que participou na cota social destinada para alunos da rede pública de ensino, que correspondia 50\% (cinquenta por cento) das vagas na UERN, no Rio Grande do Norte/RN. Nesse vestibular, o entrevistado não participou da cota de pessoas com deficiências, porque a Lei Estadual 9.696/2013 que instituída $5 \%$ (cinco por cento) para pessoas com deficiência, ainda não tinha entrado em vigor no âmbito do processo seletivo.

$\mathrm{Na}$ busca de somar experiências e efetivar ações concretas de inclusão, a UERN, através da DAIN, vem promovendo ações dentro do seu Plano Estratégico de Ação que requerem planejamento e compromisso de todos os que formam a comunidade acadêmica. A UERN, nos últimos anos, tem implementado várias iniciativas para tornar os espaços construídos mais acessíveis aos estudantes, professores e técnicos com deficiência, garantindo-Ihes a cidadania e o acesso ao meio acadêmico. Podemos corroborar a educação inclusiva na UERN pela grande quantidade de alunos com deficiência, 188 discentes, o que ratifica a participação acadêmica, social e inclusiva dessa Instituição.

Destacamos esse crescimento pelo trabalho construído pela DAIN na busca e realização de ações para a efetivação dos direitos das pessoas com deficiência no âmbito da UERN e região. Esse trabalho tem resultado em um aumento significativo do número de aprovação de candidatos com deficiência, levando aos cursos acadêmicos pessoas que antes não tinham oportunidade de ingressarem nas universidades. As condições especiais pleiteadas e consolidadas pela DAIN para a realização dos exames, com respaldo nas leis, são imprescindíveis para o resultado positivo desses candidatos, efetivando, desse modo, ações concretas de inclusão e acessibilidade nos diferentes espaços da Universidade (FREITAS, 2018).

Através das vivências no Ensino Superior narradas pelo discente com baixa visão, verificou-se o reconhecimento e a colaboração do trabalho prestado pela DAIN quanto aos elementos de acompanhamento e adequações à baixa visão. Para Herói, a ajuda da DAIN no processo de aplicação das provas do vestibular foi essencial para o ingresso na UERN. O discente comenta: 
Lembro que o pessoal da DAIN me recebeu com bastante atenção [...] eu lembro quem aplicou minha prova foi a professora Ana Lúcia Aguiar. Eu lembro que no segundo dia de prova, que eram dois dias, eu tinha deixado a redação para fazer na última hora. Eu tinha apenas praticamente meia hora para poder fazer a redação. Eu lembro que a professora Ana Lúcia, tinha até me perguntado se eu tinha feito a redação. Eu disse que não, ainda ia fazer, aí, ela tinha ficado um pouco preocupada, porque faltava poucos minutos para terminar o horário. Mas como já tinha lido o texto, na indicação da prova já sabia como fazer, metalizei como ia fazer, fui só escrevendo, né! Eu lembro que não fiz nem o rascunho, fui logo fazendo direto a redação [...] (Narrativas de Herói, em Mossoró/RN, 20/07/2017).

Para o entrevistado, as experiências nesse processo foram bastante exitosas: o discente atribui nota máxima para o trabalho da banca de adequações do vestibular e para a DAIN. A DAIN vem desenvolvendo um papel fundamental para a área da educação especial das pessoas com deficiência, especificamente no âmbito do ensino. $O$ início dos estudos na universidade causou uma preocupação para o discente:"eu tinha ingressado aqui, eram bastantes disciplinas, né? E cada disciplina era um professor diferente como é nas faculdades, diferentemente do Ensino Médio". Essa preocupação inicial é amenizada quando Herói toma conhecimento do trabalho de acompanhamento da DAIN para alunos com deficiências. Sente-se aliviado e fortalecido para continuar o curso na Universidade. Quanto ao apoio da DAIN, Herói externa sua satisfação, dizendo:

[...] tive um pouco de preocupação, mas quando eu descobri que a DAIN tinha um acompanhamento junto às faculdades, né? Um acompanhamento, digo de passagem, bem próximo, bem consolidado da forma que eu nem imaginava que eu ia ter [...] Aí, foi que eu tive mais esperança de termina o curso, né? $\mathrm{E}$, no caso das dificuldades que eu enfrento, é além da deficiência mesmo, das dificuldades que eu enfrento, não digo que seja uma dificuldades em si, mas é uma oportunidade 
como lidar com isso aí (Narrativas de Herói, em Mossoró/RN, 20/07/2017).

As atividades promovidas pela DAIN têm contribuído para a formação dos discentes com deficiência, consolidando o acesso e a permanência desses estudantes, por meio de subsídios para que haja novas possibilidades de avanços, com benefícios para uma melhor locomoção.

A DAIN promove a prática inclusiva de discentes com deficiência, que repercute, através da construção da efetivação dos direitos, a ascensão social por meio dos estudos. Como já foi mencionado, Herói mora em Icapuí/CE e seu deslocamento tornou-se uma grande preocupação para sua família. Sobre essa questão Herói relata: "é uma questão de tempo, estou me adequando, graças a Deus". Quanto à atuação na sala de aula no curso de Direito, Herói explica:

[...] os colegas me ajudam sempre. Na questão de aplicação de provas em sala de aula, tem uma atenção dos professores [...] eles ampliam as provas e corrigem com um olhar diferenciado, porque as vezes minha letra não sai um pouco visivelmente e legível, digamos assim, tem horas que eu escrevo rápido e as vezes não sai legível, com isso, os professores corrigem um pouco diferenciado [...] Até hoje, tenho certa dificuldades, no caso da minha leitura que é lenta, por exemplo, se alguém ler um texto ou uma página de um livro, vamos dizer em trinta segundos, eu já leio em um minuto, essa mesma página, então, essa é a maior dificuldade, né? Da leitura que eu tenho, hora eu prefiro ler diretamente com a lupa, porque depende também do horário do dia [...] Eu gosto de fazer experiências de não ler no notebook, né? Não ler através do leitor de tela diretamente (Narrativas de Herói, em Mossoró/RN, 20/07/2017).

Na narrativa do discente, percebemos a solidariedade e o apoio dos colegas e de professores da Faculdade de Direto. Herói agradece aos colegas pela preocupação com ele, perguntando, ocasionalmente, para o professor se a prova foi ampliada. O espirito de solidariedade de professores e alunos reflete respeito, comunhão, harmonia, cooperação e alteridade. 
Quanto às dificuldades em leitura e escrita, aos poucos Herói vai se adaptando e superando as barreiras, tanto na sala de aula quanto na convivência social. Agradece o apoio e o acompanhamento da diretoria da DAIN que, para Herói, "trabalha dia e noite para expandir a inclusão para fora dos muros da UERN". Garantir o acesso e a permanência de discentes com algum tipo de deficiência nas universidades se tornou um grande desafio. A participação da comunidade acadêmica nas atividades é frequente e, com isso, a visibilidade das pessoas com deficiência tornou-se parte da rotina da UERN, que segue o princípio do desenvolvimento de cada potencialidade dos sujeitos e valoriza as habilidades e possibilidades de cada indivíduo.

O atendimento por uma equipe especializada, multiprofissional, oferecido pela DAIN tem grande valia na inclusão dos discentes com deficiência, promovendo o desenvolvimento não somente na vida acadêmica e profissional, como também na vida pessoal e social. Esse trabalho é reconhecido por Herói:

[...] sou acompanhado pela DAIN. Na DAIN tive uma aula de braile, foi bom, porque, eu aprendi muita coisa, e atualmente faço parte de um Projeto de IniciaçãoTecnológica com a professora Ana Lúcia Aguiar, que é orientadora, tinha até me convidado para participar de um Projeto de Iniciação Científica, aí, depois que concluí Iniciação Tecnológica, ela me convidou para participar da Iniciação Científica, então, está sendo uma experiência exitosa, que eu estou tendo contato com as tecnologias, e em suma, é, o curso de Direito, é um curso muito teórico, né? E, os livros são muitos robustos para poder ler (Narrativas de Herói, em Mossoró/ RN, 20/07/2017).

A participação do discente no curso e em projetos na Universidade trouxe uma reflexão acerca da aprendizagem vivenciada no contexto do Ensino Superior, que permitiu uma relação pedagógica entre professor, discente com deficiência visual e práticas educacionais, atentando para o processo de aprendizagem pautado na inclusão, no êxito do aluno com deficiência visual e na formação de discentes e professores. Sobre as tecnologias, Herói confessa que está procurando se adequar e relata: "estou sempre curioso e procuro sempre 
o que é melhor para mim, né? E qual é o método mais adequado? Sei que todos são bons, todos os métodos são eficazes".

O Herói é um jovem cheio de ideias, não se limita, está sempre buscando formas de superar suas limitações, assim nos revela: "ainda estou à procura de um método que se use mais em questões de tempo, que eu leve menos tempo, e que eu leia mais, cada vez mais, conteúdos, cada vez mais em menos tempo". O tempo e o conhecimento tornam-se desafiadores para Herói; sua trajetória de vida e formação apontam um longo caminho para trilhar. Os desafios enfrentados pelos colegas e professores refletem um olhar metodológico nas práticas pedagógicas que superam as barreirais atitudinais em sala de aula. 


\section{Considerações}

Esta pesquisa partiu da análise de trechos de sessões de narrativas (auto)biográficas de um estudante de camada popular, com baixa visão, que permitiu uma reflexão acerca da formação do sujeito no exercício do conhecer-se e vivenciar a abertura para a alteridade, tendo como evidência o êxito social a partir dos estudos.

Os resultados apontam que o acesso e a permanência do discente na sua trajetória da Educação Básica e da Universidade é fruto do apoio familiar e do acompanhamento da Diretoria de Políticase Ações Inclusivas (DAIN) da UERN. As lições e aprendizagens promovidas pela família e pela DAIN contribuem para a formação do discente, empoderando-o na luta pela superação de barreiras arquitetônicas e atitudinais vivenciadas nos espaços social e acadêmico. As narrativas (auto)biográficas permitem um processo formativo e (auto)formativo na escrita de si e com o outro. Neste estudo, as narrativas (auto)biográficas do discente de camada popular, com baixa visão, mostraram sua ascensão social por meio dos estudos, desde a Educação Básica até o curso de Direito na Universidade - UERN.

As experiências formativas vivenciadas pelo discente entrevistado permitiram o ingresso no curso de Direito e a participação no Programa Institucional de Iniciação em Desenvolvimento Tecnológico e Inovação (PIBITI), no Programa Institucional de bolsas de Iniciação Científica (PIBIC) e em Projetos de Extensão, promovidos pela DAIN/ UERN. Essas conquistas possibilitaram para o discente uma (auto)formação e as (re)adequações necessárias ao processo de aprendizagem, haja vista o papel significativo das universidades como formadores de sujeitos que possam ter a oportunidade de conhecer e aprender com o outro, tanto no plano individual como no coletivo. 


\section{Referências}

Alberti, V. (2005). Manual de história oral. $3^{\text {a }}$ ed. Rio de Janeiro: Editora FGV.

Américo, S M. (2002). Memória auditiva e desempenho em escrita de deficientes visuais. Dissertação de Mestrado, Faculdade de Educação, Universidade Estadual de Campinas - Unicamp, Campinas-SP, Brasil.

Amiralian, M. L. T. M. (1997). Compreendendo o Cego: uma visão psicanalítica da cegueira por meio de desenhos-estórias. São Paulo: Casa do Psicólogo.

Araújo, E. H. S. (2015). Acessibilidade e Inclusão de pessoas com deficiência na Faculdade de Direito da UFBA. 2015. 86 f. il. Dissertação (mestrado) - Universidade Federal da Bahia, Instituto de Humanidades, Artes e Ciências Professor Milton Santos. Salvador.

Bittencourt, Z. Z. L. de C.; Camargo, F. P. de. (2010). Percepções do estudante comnecessidadeseducacionais especiais sobre a politica de acessibilidade na universidade. Revista Serviço Social \&
Saúde. UNICAMP Campinas, v. IX, n. 10. Disponível em: < www.bibliotecadigital. unicamp.br/>. Acesso em: 18 maio 2018.

Brasil (2004). Presidência da República. Casa Civil. Subchefia para Assuntos Jurídicos. Decreto no 5.296 de 2 de dezembro de 2004. Diário Oficial da União, 3 dez. 2004. Disponível em: < www.planalto.gov.br/>. Acesso em: 18 maio 2018.

Delory-Momberger, C. (2008). Biografia e Educação: figuras do indivíduo-projeto. Natal - RN: EDUFRN; São Paulo: Paulus.

Freitas, M. R. O. de. (2018). Sujeitos em (auto)formação: experiência pedagógica de docente na inclusão de discente com baixa visão no ensino superior. 2018. 172 f. Dissertação (Mestrado em Educação) Universidade Estadual do Rio Grande do Norte. Mossoró.

Josso, M. C. (2010). Experiência de vida e formação. 2 ed. rev. e amp. Natal, RN: EDUFRN, São Paulo: Paulus.

Mantoan, M. T. E. (2006). Inclusão Escolar: 
O que é? Por que? Como fazer? São Paulo: Moderna.

Minayo, M. C. de S. (1994) (Org.). Pesquisa social: teoria método e criatividade. 17a ed, p. 80. Petrópolis, RJ: Vozes.

Pinto, M. M. (2008). Responsabilidade social universitária como indicador de qualidadeparaoensino superior? Educere - Congresso Nacional de Educação Pontifícia Universidade Católica do Paraná, p. 186-345. Disponível em: <educere.bruc.com.br/>. Acesso em: 18 maio 2018.

Souza, E. C. de. (2007). (Auto)biografia, histórias de vida e práticas de formação. In. NASCIMENTO, AD., HETKOWSKI, TM., (Org). Memória e formação de professores [online]. Salvador: EDUFBA, 2007. p. 4871. ISBN 978-85-232-0484-6. Available from SciELO Books. Disponível em: books.scielo.org/. Acesso em: 10 jul.

\section{Para citar este artículo:}

Oliveira, A. , Brito, S. y Nogueira de Oliveira, A. Fernandes (2019). ASCENSÃO SOCIAL DE UM DISCENTE COM BAIXA VISÃO POR MEIO DOS ESTUDOS: da educação básica à universidade.

Revista Educa UMCH, 13(1). https://doi.org/10.35756/educaumch.v7i13.88 